\title{
Proton pump inhibitors in rheumatic diseases: clinical practice, drug interactions, bone fractures and risk of infections
}

\author{
Inibitori di pompa protonica in reumatologia: \\ pratica clinica, interazioni farmacologiche, \\ fratture e rischio infettivo
}

\author{
A. Laria, A. Zoli, E. Gremese, G.F. Ferraccioli \\ Division of Rheumatology, School of Medicine, Catholic University of the Sacred Heart, ClC, Rome, Italy
}

\begin{abstract}
RIASSUNTO
L'attivazione e l'aggregazione piastrinica sono elementi chiave nella patogenesi delle sindromi coronariche acute, ma anche nel danno vascolare delle malattie infiammatorie croniche e delle connettiviti (es. la sclerosi sistemica-SSc). Per tale danno i pazienti affetti da malattie infiammatorie croniche o connettiviti necessitano di terapia anti-aggregante (ex ASA o clopidogrel). Ai pazienti che assumono clopidogrel con aspirina si raccomanda l'uso di inibitori di pompa protonica (IPP) per ridurre il rischio di emorragie gastrointestinali. Sebbene tutti gli IPP abbiano una efficacia simile nella maggior parte dei casi, dovrebbero essere considerate le differenze tra loro quando si sceglie un regime di trattamento. Molti studi mostrano l'esistenza di una interazione farmacologica tra IPP e clopidogrel, con un $25 \%$ della popolazione che non risponde alla terapia con clopidogrel. Solo il pantoprazolo, che non inibisce il CYP P450 2C19, non sembra avere una interazione con il clopidogrel o altri farmaci. Particolarmente importante è l'uso nei pazienti affetti da sclerosi sistemica che hanno una alta frequenza di anomalie mucosali esofagee e dovrebbero assumere una terapia con IPP a lungo termine. Due recenti studi hanno riportato un incremento nella percentuale di fratture dell'anca con l'uso a lungo termine di IPP, supportando i dati sugli eventi avversi di questa classe di farmaci sul metabolismo minerale. L'uso di IPP è anche associato ad un maggior rischio di sviluppo di infezione da Clostridium difficile (ICD) e l'uso di IPP durante il trattamento di ICD è associato con un incremento del rischio di recidiva della stessa. Pertanto gli IPP dovrebbero essere usati in modo appropriato evitando di eccedere nella dose e nella durata della terapia. Quando necessario, l'uso del pantoprazolo potrebbe essere la scelta migliore.
\end{abstract}

Reumatismo, 2011; 63 (1): 5-10

\section{INTRODUCTION}

P atients affected by acute coronary syndrome (ACS) or by chronic inflammatory musculoskeletal and connective tissue diseases (i.e. systemic sclerosis), often need antiaggregant therapy (ASA or Clopidogrel).

The concomitant use of proton pump inhibitors (PPIs) is suggested to reduce the risk of haemorrhage. Clopidogrel is a prodrug activated by cytocrome P 450. PPIs too have a CYP P450 metabolism, and a drug interaction has been observed between PPIs and clopidogrel. 25\% of non- responsiveness to clopidogrel is due to this drug interaction (1). Some studies have demonstrated that the use of PPIs is associated with an increased risk of bone fractures and Clostridium difficile infection.

\section{CLOPIDOGREL PHARMACOGENOMICS AND RISK OF INEFFECTIVE ANTI-AGGREGATION}

Many clinical trials have demonstrated that the administration of clopidogrel together with aspirin (ASA) versus aspirin alone re-
Corresponding author: Prof. G.F. Ferraccioli Director Divisions of Rheumatology and Internal Medicine - CIC Via Moscati, 31-00168 Rome E-mail : gf.ferraccioli@rm.unicatt.it 
duces the risk of death or of recurrent acute coronary syndrome.

In particular, clopidogrel has proven beneficial in patients undergoing percutaneous coronary intervention (PCI), such that patients receiving bare metal stents and drugeluting stents are currently recommended to receive clopidogrel maintenance therapy for 1-2 months and at least 12 months, respectively (2).

Nevertheless, "clopidogrel non-responsiveness" occurs in approximately $25 \%$ of the population and it is associated with an increased risk of recurrent events (2); therefore the pharmacogenomic and pharmacodynamic knowledge of clopidogrel and the relative drug interactions became very important and the object of many studies. Clopidogrel belongs to thieno-pyridine class of chemical compounds. It is a prodrug and it is converted to its active metabolite by cytochrome P450 (CYP) enzymes. Clopidogrel is absorbed in the duodenum and approximately $85 \%$ of this dose is hydrolyzed by esterases to an inactive carboxylic acid derivative. The remaining $15 \%$ is metabolized by CYP into an active intermediate, after an oxidation of the thiophene ring.

After being released into the systemic circulation, the active metabolite's thiol group forms an irreversible disulfide bond with the platelet ADP P2Y12 receptor (P2RY12) inhibiting ADP-mediated platelet activation.

There are many isoforms of CYP P450, but the most important for PPI metabolism is the CYP2C19. This enzyme is responsible for the metabolism and clearance of many other drugs, such as cyclophosphamide, diazepam and PPI.

The CYP2C19 gene is on chromosome 10 and it contains 9 exons and it is highly polymorphic; 25 CYP2C19 variant alleles have been identified (2).

It is well established that there is an efflux pump (P-gp, ABCB1) on the bowel mucous membranes that represents a barrier to clopidogrel absorption.

Many clinical and genomic factors are responsable for clopidogrel non-responsiveness (Table I).
Table I - Predictors of clinical response to clopidogrel.

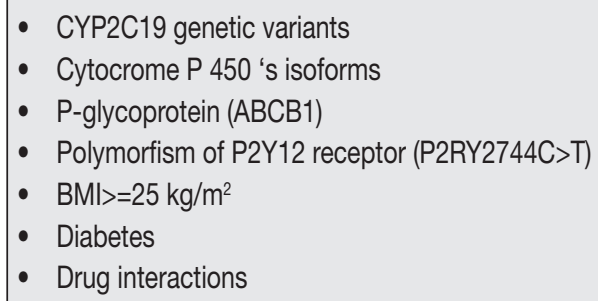

Genetic variations in other CYP isoforms (different from CYP2C19) that contribute to metabolic conversion of clopidogrel to its active metabolite in vitro have not consistently proven to be associated with clopidogrel pharmacokinetics and pharmacodynamics in humans.

CYP2C19*2 variant allele carriers are at significantly higher risk of adverse cardiovascular events compared with wild-type individuals, including death, myocardial infarction and stent thrombosis.

Polymorphism ABCB1 $3435 \mathrm{C}>\mathrm{T}$ seems to be related to a bigger outflow of the drug and then to a smaller intestinal absorption. Polymorphism of the receptor P2Y12 (P2RY2744C >T) also seems to be associated with a smaller response to antiaggregant therapy.

Diabetic and overweight individuals $\left(\mathrm{BMI}>=25 \mathrm{~kg} / \mathrm{m}^{2}\right.$ ) are significantly more likely to exhibit impaired inhibition of platelet activation, and are at higher risk of morbidity and mortality.

It is known that diabetes is associated with a pro-inflammatory and pro-thrombotic state, which may be partially mediated by hyperglycemia-induced up-regulation of P2Y12 receptor expression and increased oxidative stress. Moreover, diabetes seems to interfere with the pharmacokinetics of clopidogrel (2).

\section{PPI AND DRUG INTERACTION}

PPI can have different mechanisms through which they interfere with many drugs:

1) An increase in gastric $\mathrm{pH}$ causes a bigger absorption of weak acids (digoxin, 
furosemide, aspirin) and a smaller absorption of weak bases (ketoconazole).

2) Interference with kidney excretion.

3) Interference with CYP P450 system.

PPI and clopidogrel interaction is still an object of discussion. It is not very clear, moreover, if the clinical meaning of their interaction is more pronounced in some subsets of population (eg: specific CYP2C19 allelic variant carriers, diabetics or those overweight (2).

Different studies show the existence of drug interaction between PPI and clopidogrel (3-6).

In the OCLA study of Martine Gilard et al, a double-blind placebo-controlled trial, all consecutive patients undergoing coronary artery stent implantation received aspirin $(75 \mathrm{mg} /$ day) and clopidogrel (loading dose, followed by $75 \mathrm{mg} /$ day) and were randomized to receive either associated omeprazole $(20 \mathrm{mg} /$ day $)$ or placebo for 7 days (3).

Clopidogrel effect was tested on days 1 and 7 in both groups by measuring platelet phosphorylated -VASP expressed as a platelet reactivity index (PRI). The main end point compared PRI value at the 7-day treatment period in the 2 groups. Data for 124 patients were analyzed. On day 1 , mean PRI was $83.2 \%$ and $83.9 \%$, respectively, in the placebo and omeprazole groups $(\mathrm{p}=\mathrm{NS})$, and on day $7,39.8 \%$ and $51.4 \%$, respectively $(\mathrm{p}<0.0001)(7)$.

In a case-control study conducted by David N. Juurlink et al, among 13,636 patients prescribed clopidogrel following acute myocardial infarction, 734 cases were readmitted with myocardial infarction. After extensive multivariables adjustment, current use of PPI was associated with an increased risk of re-infarction (adjusted odds ratio [OR] 1.27, 95\% confidence interval [CI] 1.03-1.57).

In a stratified analysis, pantoprazole, which does not inhibit CYP P450 2C19, had no association with readmission for myocardial infarction (adjusted OR 1.02, 95\% CI 0.70-1.47) (8). However, a metanalysis has been published on PPI effect on cardiovascular events in patients who take clopidogrel (9). 23 studies have been found on Medline, Embase, Cochrane in October 2009. No significant increase in mortality has been found in patients who take PPI together with clopidogrel.

\section{HOW TO PREVENT COMPETITIVE INHIBITION OF CYP2C19 BY PPI}

Although each single PPI has similar efficacy in many cases, differences between them should be considered when choosing a treatment regimen. Our literature analysis shows that different PPIs are not all the same. Juurlink et al show that pantoprazole, which does not inhibit CYP P450 $2 \mathrm{C} 19$, had no drug interaction with clopidogrel (8).

These data suggest, where needed, the prescription of pantoprazole.

As PPIs and clopidogrel are each administered once daily and their presence in the bloodstream is short-lived, separating them by $12-15 \mathrm{~h}$ should in theory prevent any competitive inhibition of CYP metabolism and any clinical effect. In addition, PPIs are most effective when taken before meals. Therefore, it is suggested that PPIs be given before breakfast and clopidogrel at bedtime, or, to minimize concern about poor CYP2C19 metabolizers, PPIs may be taken before dinner and clopidogrel at lunchtime (1).

\section{PPI AND BONE FRACTURES}

Patients affected by chronic systemic inflammatory or connective tissue diseases i.e. systemic sclerosis, have high frequency of oesophageal mucosal abnormalities and should take long-term PPI therapy.

It has been suggested that an acidic environment in the stomach and upper small bowel is required to free ingested calcium from the food matrix making it available for absorption. Impaired calcium absorption would lead to compensatory physiologic responses, including secondary hyperparathyroidism.

Secondary hyperparathyroidism refers to 
the increase in circulating levels of parathyroid hormone when serum levels of ionized calcium drop (as would occur with reduced efficiency in intestinal calcium absorption). Over time, parathyroid hormone would lead to an increase in the rate of skeletal turnover and a reduction in bone mass, both of which increase the risk of fracture (10).

If normal gastric acid production is required for calcium ionization and subsequent absorption, then the millions of individuals using PPIs may be at increased risk for calcium malabsorption, negative calcium balance, and potential bone loss. Unfortunately, there are no long-term studies on the effects of PPIs on calcium absorption (11).

Today, we have only short-term studies examining the effect of gastric acid suppression on calcium absorption and bone turnover (12-16).

A MEDLINE search was conducted to identify relevant articles regarding PPIs and fractures (10).

Three case-control studies assessed fractures and PPI use. A study of all subjects with fracture in Denmark in 2000 revealed adjusted OR=1.18 (1.12-1.43) for PPI use within the last year (hip fracture $\mathrm{OR}=1.45$, 1.28-1.65); no dose-response relationship was identified (17).

A study of hip fractures in UK patients $\geq 50$ years found adjusted $\mathrm{OR}=1.44(1.30-1.59)$ for $>1$ year of PPIs; duration and average daily dose were significantly associated with fracture risk: adjusted OR for $>1.75$ times average daily dose for $>1$ year was 2.65 (1.80-3.90) (18).

A study of vertebral, wrist, and hip fractures in Manitoba patients $\geq 50$ years found significant $\geq 7$ years $(\mathrm{OR}=1.92,1.16-3.18)$ (19) risk factor.

\section{PPI AND RISK OF CLOSTRIDIUM DIFFICILE INFECTION (CDI)}

Clostridium difficile (CD) is a Gram-positive, spore-forming, anaerobic bacillus.
The PPI's use increases the risk of CDI. In a case-control study performed on hospitalized patients, PPI use was associated with C. difficile diarrhoea (OR 2.7, 95\% confidence interval (CI) 1.4-5.2) and with relapse (OR 5.2, 95\% CI 1.1-24.6) (20).

Another study showed that hospitalized patients using PPIs were 4.2-fold more likely to have recurrent disease. This risk was not observed in patients using $\mathrm{H} 2$ blockers (21).

Probably, the chronic use of PPIs, reducing gastric acid environment, reduces a natural defense of our organism.

Also in the community PPI use was associated with an increase in CDI (OR 2.9, 95\% CI 2.4-3.4) (22).

Recently a retrospective cohort study has been published.

It shows a risk of recurrent CDI higher in patients taking PPIs versus patients not exposed to this class of drugs $(25.2 \%$ vs $18.5 \%$ ) with a $42 \%$ increased risk of recurrence (23).

CDI has been demonstrated to be rarely associated with reactive arthritis, a condition that may develop in response to a gastrointestinal infections usually due to Salmonella, Shigella, Yersinia or Campylobacter (24).

Recently 46 cases in adults have been reported. The sex ratio was close to 1 and the patients were older than those with other causes of reactive arthritis (25).

\section{CONCLUSIONS}

In several long term therapeutic programs PPI should be adopted as a protection to the stomach or to avoid gastroesophageal reflux disease (GERD).

It appears very clear that the choice of PPI in several cases should be made on a carefully assessed risk/benefit ratio assessment.

In particular a thoughtful analysis should be performed in all patients needing antiplatelet therapy and in all patients with osteoporosis, either primary or secondary. 


\section{SUMMARY}

Platelet activation and aggregation are key elements of the pathogenesis of acute coronary syndromes, of endothelial damage in chronic inflammatory and connective tissue disease (i.e. systemic sclerosis-SSc). Patients affected by chronic inflammatory diseases as well as by connective tissue diseases such as systemic sclerosis, often have the need to take anti-platelet therapy (e.g. ASA or clopidogrel). Current consensus recommendations state that patients prescribed clopidogrel plus aspirin should receive a proton pump inhibitor (PPI) to reduce gastrointestinal bleeding. Although each single PPI has similar efficacy in many cases, differences between them should be considered when choosing a treatment regimen. Many studies show PPI and clopidogrel drug interaction, with clopidogrel non-responsiveness in about $25 \%$ of the population. Only pantoprazole, which does not inhibit CYP P450 2C19, doesn't seem to have interaction with clopidogrel or other drugs. Patients affected by systemic sclerosis have high frequency of oesophageal mucosal abnormalities and should take long-term PPI therapy. When addressing long-term therapy safety data are clearly needed. Two recent studies have reported increased hip fracture rates with long-term PPI use, raising concerns about adverse effects of this class of drugs on mineral metabolism. The use of PPIs is also associated with an increase in the risk of development of Clostridium difficile infection (CDI) and the use of PPIs during CDI treatment is associated with an increased risk of recurrence.

In order to achieve the desired results and, as with all medications, PPIs should always be used appropriately taking care never to exceed correct dosage and duration. When necessary use of pantoprazole arises as one of the best possible choices.

Parole chiave: Inibitori di pompa, fratture, sindrome coronarica acuta, interazioni farmacologiche. Key words: Proton pump inhibitor; cytochrome P450; clostridium difficile; bone fractures; drug interactions; acute coronary syndrome; systemic sclerosis.

\section{REFERENCES}

1. 1. Laine L, Hennekens C. Proton pump inhibitor and clopidogrel interaction: fact or fiction? Am J Gastroenterol 2010; 105: 34-41.

2. Ellis KJ, Stouffer GA, McLeod HL, Lee CR. Clopidogrel pharmacogenomics and risk of inadequate platelet inhibition: US FDA recommendations. Pharmacogenomics 2009; 10: 1799-817.

3. Gilard M, Arnaud B, Le Gal G, Abgrall JF, Boschat J. Influence of omeprazol on the antiplatelet action of clopidogrel associated to aspirin. J Thromb Haemost 2006; 4: 2508-9.

4. Sibbing D, Morath T, Stegherr J, Braun S, Vogt W, Hadamitzky M, et al. Impact of proton pump inhibitors on the antiplatelet effects of clopidogrel. Thromb Haemost 2009; 101: 714-9.

5. O’ Donoghue ML, Braunwald E, Antman EM, Murphy SA, Bates ER, Rozenman Y, et al. Pharmacodynamic effect and clinical efficacy of clopidogrel and plasugrel with or without a proton pump inhibitor: an analysis of two randomized trials. Lancet 2009; 374: 989-97.

6. Pezalla E, Day D, Pulliadath I. Initial assessment of clinical impact of a drug interaction between clopidogrel and proton pump inhibitors. J Am Coll Cardiol 2008; 52: 1038-9.

7. Gilard M, Arnaud B, Cornily JC, Le Gal G, Lacut K, Le Calvez G, et al. Influence of omeprazole on the antiplatelet action of clopidogrel associated with aspirin: the randomized, double-blind OCLA (Omeprazole
CLopidogrel Aspirin) study. J Am Coll Cardiol 2008; 51: 256-60.

8. Juurlink DN, Gomes T, Ko DT, Szmitko PE, Austin PC, Tu JV, et al. A population-based study of the drug interaction between proton pump inhibitors and clopidogrel. CMAJ 2009; 180: 713-8.

9. Kwok CS, Loke YK. Meta-analysis: the effects of proton pump inhibitors on cardiovascular events and mortality in patients receiving clopidogrel. Aliment Pharmacol Ther 31; 810-23.

10. Laine L. Proton Pump Inhibitors and Bone Fractures? Am J Gastroenterol 2009; 104: S21-S26.

11. Insogna KL. The effect of proton pump inhibiting drugs on mineral metabolism. Am J Gastroenterol 2009; 104: S2- S4.

12. Graziani G, Badalamenti S, Como G, Gallieni M, Finazzi S, Angelini C, et al. Calcium and phosphate plasma levels in dialysis patients after dietary Ca-P overload. Role of gastric acid secretion. Nephron 2002; 91: 474-9.

13. Graziani G, Como G, Badalamenti S, Finazzi S, Malesci A, Gallieni M, et al. Effect of gastric acid secretion on intestinal phosphate and calcium absorption in normal subjects. Nephrol Dial Transplant 1995; 10: 1376-80.

14. Hardy P, Sechet A, Hottelart C, Oprisiu R, Abighanem O, Said S, et al. Inhibition of gastric secretion by omeprazole and defeciency of calcium carbonate on the control of hyperphosphatemia in patients on chronic hemodialysis. Artif Organs 1998; 22: 569-73.

15. O' Connell MB, Madden DM, Murray AM, 
Heaney RP, Kerzner LJ. Effects of proton pump inhibitors on calcium carbonate absorption in women: a randomized crossover trial. Am J Med 2005; 118: 778-81.

16. Serfaty-Lacrosniere C, Wood RJ, Voytko D, Saltzman JR, Pedrosa M, Sepe TE, et al. Hypochlorhydria from short-term omeprazole treatment does not inhibit intestinal absorption of calcium, phosphorus, magnesium or zinc from food in humans. J Am Coll Nutr 1995; 14: $364-8$.

17. Vestergaard P, Rejnmark L, Mosekilde L. Proton pump inhibitors, histamine $\mathrm{H} 2$ receptor antagonists, and other antacid medications and the risk of fracture. Calcif Tissue Int 2006; 79: 76-83.

18. Yang YX, Lewis JD, Epstein S, Epstein S, Metz DC. Long-term proton pump inhibitor therapy and risk of hip fracture. JAMA 2006; 296: 2947-53.

19. Targownik LE, Lix LM, Metge CJ, Prior HJ, Leung S, Leslie WD. Use of proton pump inhibitors and risk of osteoporosis-related fractures. CMAJ 2008; 179: 306-7.

20. Dial S, Alrasadi K, Manoukian C, Huang A,
Menzies D. Risk of Clostridium difficile diarrhea among hospital inpatients prescribed proton pump inhibitors: cohort and case-control studies. CMAJ 2004; 171: 33-8.

21. Cadle RM, Mansouri MD, Logan N, Kudva DR, Musher DM. Association of proton-pump inhibitors with outcomes in Clostridium difficile colitis. Am J Health Syst Pharm 2007; 64: 2359-63.

22. Dial S, Delaney JA, Barkun AN, Barkun AN, Suissa S. Use of gastric acid-suppressive agents and the risk of community-acquired Clostridium difficile-associated disease. JAMA 2005; 294: 2989-95.

23. Linsky A, Gupta K, Lawler EV, Fonda JR, Hermos JA. proton pump inhibitors and risk for recurrent clostridium difficile infection. Arch Intern Med 2010;170: 772-8.

24. Birnbaum J, Bartlett JG, Gelber AC. Clostridium difficile: an under-recognized cause of reactive arthritis? Clin Rheumatol 2008; 27: 253-5.

25. Prati C, Bertolini E, Toussirot E, Wendling D. Reactive arthritis due to Clostridium difficile. Joint Bone Spine 2010; 77: 190-2. 